\title{
REFLEXÕES SOBRE O CRIME DE USURA NO DIREITO BRASILEIRO
}

REFLECTIONS ON THE CRIME OF USURY IN BRAZILIAN LAW

NILO BATISTA*

\section{RESUMO}

Neste artigo, o delito de usura é analisado em profundidade de acordo com a legislação brasileira.

\section{PALAVRAS-CHAVES}

Delito de usura, usura pecuniária, usura real.

\begin{abstract}
In this paper, the crime of usury is analyzed in depth according to Brazilian law.
\end{abstract}

\section{KEY WORDS}

Crime of usury, pecuniary usury, real usury.

Artículo recibido para su evaluación el 2 de noviembre de 2020, y aprobado para su publicación el 20 de diciembre de 2020.

* Professor titular de direito penal que foi da Universidade Federal do Rio de Janeiro, da Universidade do Estado do Rio de Janeiro e da Universidade Candido Mendes. Presidente do Instituto Carioca de Criminologia. 


\section{NOTÍCIA HISTÓRICA.}

A proibição - total ou parcial (neste caso, pela prescrição de taxa) - da usura foi uma constante nas sociedades antigas, da Mesopotâmia ${ }^{1}$ à Índia ${ }^{2}$, da Grécia ${ }^{3}$ a Roma ${ }^{4}$. Tal constância se explica, como ensinou Santarelli, pelo "contexto de economia agro-pastoril de subsistência" dessas sociedades ${ }^{5}$. Para homens que viviam e se reproduziam numa economia com essas características soava como um despropósito confiscatório que ao empréstimo de certa quantidade de grãos, de gado ou depois de moeda não correspondesse uma devolução estritamente idêntica. A comistão entre cultos religiosos e normas jurídicas na antiguidade explica como a proibição inscreveu-se nas chamadas "religiões do Livro", incorporandose ao Pentateuco ${ }^{6}$, ao Evangelho ${ }^{7}$ e - já na alta idade média - ao Corão. Um protagonismo especial caberia ao direito canônico. Dinamizado pelas burocracias judiciais eclesiásticas e pela sua própria expansão na Europa cristianizada, em cujo território - ao lado do direito romano - constituiria no futuro um "direito comum", o direito canônico difundiu a proibição da usura e influenciou neste sentido dos ordenamentos locais do baixo medievo aos modernos direitos dos Estados nacionais em formação? Metade pecado, metade delito, a usura é um tema que se apresenta no desenvolvimento não apenas de todos os sistemas jurídicos que integram ou provêm da "família" romano-germânica continental como o nosso, mas também em outras "famílias".

$1 \quad$ BOUZON, Emanuel (org.): As Leis de Eshunna. ed. Vozes, Petrópolis, 1981.pp. 82 ss (§ 18 a); do mesmo (org.), O Código de Hammurabi. ed. Vozes, Petrópolis, 1976. p. 49.

2 OLIVELlE, Patrick: Manu's Code of Law. ed. Un. Oxford, N. Delhi, 2005. p.174.

3 "É com justa razão que nos repugna a usura" (Aristóteles: A Política, 1258b). Cf. trad. de N.S.Chaves. ed. Edipro, Bauru, 2009. p. 31.

4 Desde a lei das XII Tábuas: MOMMSEN, Theodor: Droit Pénal Romain. trad. J. Duquesne, ed. A. Fontemoing, Paris, 1907, t. $3^{\circ}$, p. 174; do mesmo, Historia de Roma. trad. A. G. Moreno. ed. Aguilar, Madri, 1957, v. I. p. 301.

5 SANTARELLI, Umberto: La prohibición de la usura, de canon moral a regla jurídica. em Petit, Carlos (org.) .Del Ius Mercatorum al Derecho Mercantil. Marcial Pons, Madrid, 1997. pp. 237 ss. (o trecho citado na p. 239).

6 P. ex. Deuteronômio, 23, 19 e 20 (“A teu irmão não emprestarás com juros”).

7 P. ex. Lucas, 6, 35 ("Emprestai sem esperar nenhuma paga").

8 P. ex. $2^{\text {a }}$ Surata, 275 (“Allah consente o comércio e veda a usura").

9 Uma síntese do tratamento da usura pelo direito canônico histórico em BATISTA, Nilo: Matrizes Ibéricas do Sistema Penal Brasileiro. ed. Revan, Rio, 2000, v. I. pp. 221 ss. 
Se neste longo percurso por muitas vezes o pensamento jurídico - inclusive o canônico ${ }^{10}$ - e as leis transigiram com a proibição da usura, a partir do século XVIII o liberalismo econômico a ela se opôs explicitamente ${ }^{11}$. Naquela ocasião, a própria igreja católica abandonou a ortodoxa e incondicional condenação da usura ${ }^{12}$. Contudo, conjunturas de crise financeira e, já no século $\mathrm{XX}$, as intervenções do Estado no planejamento e em atividades econômicas ressuscitariam ciclicamente aquela proibição.

Essa amplitude multimilenar e planetária do assunto, aliada à variedade proteiforme das diversas disciplinas legais, torna compreensível a desolação com a qual o grande penalista suíço Paul Logoz, observando não só a sucessão diacrônica de leis divergentes, mas também a convivência - em diferentes cantões - de soluções legais díspares, queixava-se de que o desenvolvimento histórico da usura se caracterizava não só pela "diversidade de concepções que se manifestam umas depois das outras (les unes après les autres)" mas também "umas ao lado das outras (les unes à coté des autres)" "13.

Portanto, a reconstrução dogmática do delito de usura deve precaver-se quanto a argumentos provenientes de interpretação histórica ou de direito comparado. Feita essa advertência, podemos nos aproximar de nosso objeto e até mesmo ilustrar os riscos aos quais se submete quem não a leva em conta.

Ao contrário do que previam as legislações penais que mais influenciaram a nossa em meados do século XX, isto é, da italiana, da alemã e da suíça, a lei brasileira decompôs o delito de usura em dois tipos legais autônomos: o da usura pecuniária e o da usura real. Essa opção de técnica

10 Tomás de Aquino, temperando a proibição, admitia fosse no mútuo recebida uma compensação pelo prejuízo que a privação do próprio bem ocasionara ao mutuante ("recompensationem damni per quod subtrahitur sibi aliquid quod debet haberi"); não haveria pecado no plus que fosse pago "ad recompensationem nocumenti" (Summa Theologiae, II-II, Q. 78, a. 2, sol. $1^{\circ}$ e a. 3, resp.).

11 Por todos, mencione-se o livro de Jeremy Bentham, Defense of Usury, que veio a lume em 1787.

12 Na encíclica Vix pervenit, de 1745, o papa Bento XIV, mantendo embora a proibição para o mútuo, que deveria ser gratuito, admitia que em algum "altro contratto diverso dal mutuo" fosse lícito "obter um pequeno lucro (ricavare un modesto guadagno)". Cf. Vix pervenit, item $\mathrm{V}$.

13 LOGOZ, Paul: Commentaire du Code Pénal Suisse. ed. C. e Niestlé, Neuchâtel, 1955, P.S., v. I. p. 183. 
legislativa já se esboçava em nossa primeira ${ }^{14}$ efetiva criminalização da usura $^{15}$, a do decreto-lei ${ }^{\circ} 869$, de 18.nov.1938:

"Art. $4^{\circ}$ Constitui crime da mesma natureza a usura pecuniária ou real, assim se considerando:

a) cobrar juros superiores à taxa permitida em lei, ou comissão ou desconto, fixo ou percentual, sobre a quantia mutuada, além daquela taxa;

b) obter ou estipular, em qualquer contrato, abusando da premente necessidade, inexperiência ou leviandade da outra parte, lucro patrimonial que exceda ao quinto do valor corrente ou justo da prestação feita ou prometida.

É sabido que o informal redator desse texto legal foi Nelson Hungria ${ }^{16}$, inspirado no particular pelo código penal alemão de 1871, que originalmente não previa o crime de usura (introduzido em seu artigo 302 por leis de 1880 e 1893) e pelo tipo legal de usura do código Rocco ${ }^{17}$.

Ocorre que tanto no direito penal alemão quanto no italiano a usura se apresenta como unitário tipo misto alternativo, que embora emparelhe a usura pecuniária (Kreditwucher ou Geldwucher) à usura real (Geschäftswucher ou Sachwucher) subordina ambas ao aproveitamento da vulnerabilidade da vítima.

14 Como se sabe, lei de 24 de outubro de 1832, inspirada em Bentham (um dos autores mais citados nos debates parlamentares que resultaram no Código Criminal do Império, de 1830), determinava em seu art. $1^{\circ}$ que "o juro ou prêmio de dinheiro, de qualquer espécie, será aquele que as partes convencionarem”. Só na década de 1930 a usura seria criminalizada entre nós.

15 A imperfeita tipificação do decreto $\mathrm{n}^{\circ} 22626$, de 7.abr.1933 (cujo art. 13 criminalizava a "simulação tendente a ocultar a verdadeira taxa de juro" e lançava à imprecisão de "fraudar as disposições desta lei" - cujo art. $1^{\circ}$ estabelecia o patamar do dobro da taxa legal - a própria conduta usurária) seria, um lustro depois, revogada e aperfeiçoada pelo decreto-lei n ${ }^{\circ} 869$, de 18.nov.1938.

16 A quem Elias de Oliveira se refere como o "brilhante e culto autor intelectual do Decretolei $\mathrm{n}^{\mathrm{o}} 869$, de onde a lei $\mathrm{n}^{\circ} 1.521$ copiou, nessa parte, o texto" (DE OLIVEIRA, Elias: Crimes contra a Economia Popular. ed. F. Bastos, Rio, 1952. p. 170).

17 Como registrou Oscar Stevenson, "a fonte próxima das duas alíneas do art. $4^{\circ}$ (foram) o art. 302, $a$ e $e$, do código alemão (e) o conteúdo de ambas coincide em linhas gerais com o do art. 644 do diploma italiano" (Aspectos do crime de usura, em RT, 169/ 3ss [trecho citado na p. 10]). 
Assim, no direito penal alemão vigente (§ $291 S t G B)$ é indispensável que o agente da usura se aproveite do "estado de constrangimento" (ou de "pressão" - Zwangslage), ou da "inexperiência (Unerfahrenheit)", ou da "falta de discernimento (Mangel an Urteilsvermögen)" ou da "grave debilidade de vontade (erhebliche Willensschwäche)" do sujeito passivo. Também no direito penal italiano (art. $644 C P I$ ) não se caracteriza o delito se ausente a exploração do "estado de precisão (stato di bisogno)" da vítima ${ }^{18}$, e o direito penal suíço (art. $157 C P S$ ) exige que o agente se prevaleça do "estado de embaraço econômico ou dependência (état de gêne ou de dependence)", ou da "fraqueza de espírito (faiblesse d'esprit)", ou da "inexperiência (inexpérience)", ou da "tibieza de caráter (faiblesse de caractère)" ou por fim da "leviandade (légèreté)" do sujeito passivo. Para o direito penal brasileiro, esses requisitos típicos se apresentam na usura real, não porém na usura pecuniária.

Como no direito penal alemão que o inspirara qualquer usura constituía crime material ${ }^{19}$, Hungria entendeu que o momento consumativo da usura pecuniária ("Cobrar juros superiores...") residiria no recebimento dos juros onzenários, sem o que teríamos mera tentativa ${ }^{20}$. Doutrina ${ }^{21}$ e jurisprudência ${ }^{22}$ divergiram desse entendimento, cobertas ambas de

18 A especial articulação, no código italiano, da usura à circonvenzione di persone incapaci (art. $643 \mathrm{CPI}$ ), tipo que corresponde ao nosso abuso de incapazes (art. $173 \mathrm{CP}$ ) e se ocupa portanto das deficiências psíquicas ou físicas do sujeito passivo, reduziu o aproveitamento ao stato di bisogno (que, em compensação, inflou-se de significados).

19 Tratando da usura pecuniária - dentro do modelo legal unitário - von Liszt afirmava que o crime requisitava "dano patrimonial (Vermögensbeschädigung)" (von LISZT, Franz: Lehrbuch des Deutschen Strafrechts. ed. W. de Gruyter, Berlim, 1919. p. 469).

20 "Cobrar significa receber e, assim, enquanto o agente não embolsa o prêmio exorbitante, o que pode apresentar-se é uma tentativa de usura pecuniária" (HUNGRIA, Nelson: Dos Crimes contra a Economia Popular. ed. Jacintho, Rio, 1935. p. 166).

21 Dele discordaram entre nós, com argumentos irrefutáveis, AZEVEDO, Noé: A repressão penal da usura em Estudos-homenagem a Nelson Hungria. ed. Forense, Rio, 1962. p. 143; DE OLIVEIRA, cit., p. 170; SOUZA NETO: Júri de Economia Popular. ed. Forense, Rio, 1952. pp. 114; e MANTECCA, Paschoal: Crimes contra a Economia Popular e sua Repressão. ed. Saraiva, S. Paulo, 1985. p. 44. Essa opinião prevalece também na doutrina italiana e suíça. Para Antolisei, "a consumação se verifica no momento em que os juros usurários são dados ou simplesmente prometidos ou seja, no momento da contratação (dela pattuizione)." ANTOLISEI, Francesco: Manuale di Diritto Penale. ed. Giuffrè, Milão, 1972, P.S., v. I. p. 286). Para Logoz, o crime de usura está consumado quando a vítima "concordou ou prometeu (a accordé ou promis) ao usurário tais vantagens". LOGOZ, cit., p. 186.

22 TJSP, rel. Des. Lauro Malheiros, RT 551/339; TACrimSP, rel. J.Aguiar Vallim, RJD 11/66 (apud A. SILVA FRANCO, A. e StOCO, R.: Leis Penais Especiais e sua Interpretação Jurisprudencial. ed. RT, S. Paulo, 2001, v. 1. p. 1471); STJ, HC 17.943/SP, $5^{\mathrm{a}}$ T., rel. 
carradas de razão. Mesmo um penalista erudito e perspicaz como Hungria confundiu-se no calidoscópio em constante mutação das instáveis estruturas típicas do delito de usura.

\section{SOBRE USURA PECUNIÁRIA.}

O tipo legal da usura pecuniária se estampa no artigo $4^{\circ}$, alínea $a$, da lei $\mathrm{n}^{\circ}$ 1.521, de 2.dez.1951. Trata-se de um tipo misto cumulativo, que contempla três condutas desconexas: $1^{\text {a }}$ ) a cobrança de juros, comissões ou descontos percentuais, sobre dívidas em dinheiro, superiores à taxa permitida por lei; $2^{\mathrm{a}}$ ) a cobrança de ágio superior à taxa oficial de câmbio, sobre quantia permutada por moeda estrangeira; e $3^{a}$ ) o empréstimo sob penhor que seja privativo de instituição oficial de crédito.

Neste pequeno estudo limitar-nos-emos ao exame da primeira modalidade que é aquela estatisticamente mais relevante. Ficará para outra ocasião a análise da segunda (o neoliberalismo abomina taxas oficiais de câmbio, que só atrapalham a sabedoria da mão invisível do mercado) e da terceira (como pode uma "instituição oficial de crédito" deter o monopólio de uma forma de garantia real?!) modalidades. Assim, apenas nos ocuparemos da seguinte estrutura típica:

"cobrar juros, comissões ou descontos percentuais, sobre

dívidas em dinheiro, superiores à taxa permitida por lei”.

O delito de usura pressupõe um contrato; alguns autores o situam numa classe chamada "delitos-contrato" 23 . Mas a usura pecuniária, que é a forma mais antiga e tradicional do delito, pressupõe um contrato de mútuo. Foi em torno do mútuo que se originou e se expandiu essa proibição mística.

No direito romano, das origens - não fôra Roma uma sociedade agrária - até a decadência do império ${ }^{24}$ o mútuo era um contrato gratuito. Como ensinou Bonfante,

"a pactuação de juros é incompatível com o mútuo, pois não responde a sua causa tipicamente fixa, que não admite uma restituição senão na

Min. Jorge Scartezzini, DJU 24.mai.2004; STJ, REsp. 569.496/SP, 5 T., rel. Min. Gilson Dipp, DJU 19.dez.2003.

23 Para a usura entre os "reati-contratto", cf. GRISPIGNI, Filippo: Diritto Penale Italiano. ed. Giuffrè, Milão, 1950, v. II. pp. 234 ss.

24 Uma constituição de Justiniano de meados do século VI irá revogar a proibição (egregium praescriptum abrogamus) para autorizar que o mútuo produza juros (ut mutui usus ad usuras procedat); cf. Novellae, const. LXXXIII. 
medida da dação (quatenus dat sit) ou, se avençado, em medida inferior, porém jamais superior" 25 .

Nosso Washington de Barros Monteiro registrava igualmente que "de início o mútuo era desinteressado e, pois, inteiramente gratuito"26. Assinalam com precisão Masnatta e Bacigalupo que no direito romano "o mútuo integrava os contratos a título gratuito, nos quais prevalecia a idéia de benignitas, pietas, amicitia; (...) o mutuário podia obrigar-se a devolver menos do que o recebido, porém nunca mais"27. Quando o liberalismo econômico, a partir do século XVIII, ainda enfrentava essa arraigada concepção do mútuo, a solução para os cristãos - afinal, a palavra mútuo estava no Evangelho ${ }^{28}$ - foi manter a proibição para o mútuo mas permitir o "modesto guadagno" de que falou Bento XIV em outros contratos ${ }^{29}$. Para que se tenha uma idéia dessa interdependência, basta recordar que, em seu monumental Direito Privado Europeu, Coing estudou a usura como um tópico do mútuo ${ }^{30}$ !

Na literatura penalística há unanimidade quanto a constituir o mútuo, real ou simulado, a indispensável base objetiva da usura pecuniária. Mesmo os sistemas unitários (que num único tipo legal versam a usura pecuniária e a usura real) não negarão ao mútuo seu protagonismo ${ }^{31}$.

25 BONFANTE, Pietro: Instituciones de Derecho Romano, trad. L. Bacci e A. Larrosa. ed. Reus, Madrid, 1965. p. 480.

26 DE BARROS MONTEIRO, Washington: Curso de Direito Civil. ed. Saraiva, S. Paulo, 1962 , v. $2^{\circ}$. p. 228.

27 MASNATTA, Hector e BACIGALUPO, Enrique: Negocio Usurario. ed. Astrea, B. Aires, 1972, ed. Astrea. p. 17.

28 A passagem de Lucas, citada na nota $\mathrm{n}^{\circ}$ 7, tem a seguinte redação em latim: "Mutuum date nihil inde sperantes".

29 Cf. nota $\mathrm{n}^{\circ}$ 12. Aliás, Bento XIV, ao mencionar o "pecado que se chama usura", observava ter ele "no contrato de mútuo sua própria colocação e seu próprio posto" (Vix pervenit, item I). Nosso jusnaturalista Tomás Antonio Gonzaga, autor do primeiro estudo sobre a usura escrito no Brasil, fazia exatamente isso, nas pegadas da encíclica. Para ele, os juros eram possíveis em "contrato inominado, a que alguns autores chamam feneratício, bem que as partes impropriamente o apelidem mútuo", jamais no "rigoroso mútuo". Cf. GONZAGA, Tomás A.: Carta sobre a Usura, em Obras Completas. ed. INL, Rio, 1957, v. II. pp. 155 ss (trechos transcritos nas pp. 158 e 159).

30 COING, Helmut: Derecho Privado Europeo, trad. A.P. Martín. ed. Fund. Cult. Notariado, Madrid, 1996, v. I. pp. 592 e 601.

31 Ao conceituar a usura pecuniária simples, Welzel destacará a "usura com cobertura num empréstimo (Wucher mit Bezug auf ein Darlehen)." WELZEL, Hans: Das Deutsche Strafrecht. ed. W. de Gruyter, Berlim, 1969. p. 391). A tradição e a recorrência da usura pecuniária explicam "a terminologia corrente de mutuante e mutuário para designar (per 
Para Landrove Diaz, "a conduta, substrato essencial da ação delituosa, é evidente que vem constituída pela relação contratual de empréstimo (relación contractual de préstamo) existente entre o sujeito ativo e o passivo"32. Ocupando-se estritamente da usura pecuniária ("usura de crédito"), Damianovich ensina que "tal forma de usura deve circunscrever-se ao caso do mútuo e sob nenhum pretexto (bajo ningún concepto) será extensiva a outro tipo de empréstimo" "33. Ao elaborar sua definição de negócio usurário, Ernesto Ure o projeta "nos contratos de mútuo feneratício"34. "Na usura pecuniária" - lecionava Souza Neto - "cobra-se, no empréstimo, preço (prêmio) exorbitante pelo uso do dinheiro" 35 . O clássico Goyet frisava: para que o delito de usura pecuniária "esteja caracterizado é necessário que se trate de um empréstimo contratual (il faut qu'il s'agisse d'un prêt conventionnel)" ${ }^{36}$. Sinteticamente, Dupont-Delestraint: "o delito de usura pressupõe (suppose) um empréstimo"37. Para Oscar Stevenson existe usura pecuniária "quando exorbitantes do máximo legal os juros, comissões e descontos sobre o dinheiro mutuado", frisando que esse tipo legal "apenas focaliza o mútuo de dinheiro (...) e não contratos outros" ${ }^{38}$. Também Elias de Oliveira atrela a usura de crédito ao "mútuo pecuniário"39.

É claro que pode haver usura pecuniária num contrato de mútuo simulado, travestido de outra roupagem jurídica: tais simulações foram chamadas de usuras encobertas (usurae palliatae). Isso pode ocorrer sob incontáveis disfarces: na compra e venda com opção de retrovenda, na negociação de títulos de crédito etc ${ }^{40}$. A dissimulação do mútuo usurário configura entre nós uma agravante (art. $4^{\circ}, \S 2^{\circ}$, inc. III da lei 1.521/51). De qualquer modo, é indispensável que a natureza verdadeira do contrato simulado resida num mútuo.

indicare) o sujeito ativo e aquele passivo do delito em exame" (LA PORTA, Romualdo: Il Delitto di Usura. ed. Ateneo, Roma, 1952. p. 29).

32 LANDROVE DIAZ, Gerardo: El Delito de Usura. ed. Bosch, Barcelona, 1968. p. 141.

33 DAMIANOVICH, Laura T.A.: El Delito de Usura. ed. Ediar, B. Aires, 1971. pp. 83-84.

34 URE (h.), Ernesto: Usura en el Derecho Penal. ed. Ab.-Perrot, B. Aires, 1967. p. 13.

35 SOUZA NETO: Júri de Economia Popular. ed. Forense, Rio, 1952. p. 115.

36 GOYET, F.: Droit Pénal Spécial, $8^{\mathrm{a}}$ ed. (rev. e at. por Rousselet, Patin e Arpaillange). ed. Sirey, Paris, 1972. p. 757.

37 DUPONT-DELESTRAINT, Pierre: Droit Pénal des Affaires. ed. Dalloz, Paris, 1974. p. 354.

38 Aspectos do crime de usura, cit. pp. 9 e 10.

39 Crimes contra a Economia Popular, cit., p. 168.

40 Cf. COSER, José Reinaldo: JUROS. ed. LED, Leme, 2000. p. 41. A jurisprudência francesa autoriza o juiz a verificar se o contrato ostensivo (particularmente a retrovenda, vente à réméré) não oculta um mútuo (cf. GOYET, cit., p. 757, nota 1). 
Não pode portanto haver usura pecuniária se não houver "quantia mutuada" (expressão que integrava o tipo legal no decreto-lei $\mathrm{n}^{\circ}$ 869, de 18.nov.1938) ou "divida em dinheiro" (expressão que integra o tipo legal vigente do artigo $4^{\circ}$, alínea $a$, da lei $\mathrm{n}^{\circ} 1.521$, de 26.dez.1951).

Na usura pecuniária, a conduta típica do sujeito ativo - o mutuante, aquele que está emprestando ou emprestou dinheiro - consiste precisamente em cobrar juros, comissões ou descontos percentuais sobre a quantia emprestada (a "dívida em dinheiro") superiores à taxa permitida em lei. A cobrança do mutuante é endereçada ao mutuário, a quem está tomando ou tomou o empréstimo (sujeito passivo).

Juros "são o fruto, o rendimento do capital emprestado"41. Evidentemente, o sujeito ativo - aquele que cobra juros - é o mutuante, é quem emprestou o dinheiro, é o credor. Comissões são "certas quantias que se deduzem em remuneração do serviço de empréstimos ou descontos" ${ }^{\text {"42. }}$. Também aqui o sujeito ativo - aquele que cobra comissões - é o mutuante, é quem emprestou o dinheiro, é o credor. Descontos tem no contexto típico o significado de "redução a que se submete a soma de certa importância, (...) o abatimento que é feito no total de qualquer soma em dinheiro"43. Também aqui o sujeito ativo - aquele que cobra um desconto percentual sobre dívida em dinheiro - é o mutuante, é quem emprestou o dinheiro, é o credor. Neste último caso, é frequente que o "desconto" esteja representado pela diferença entre a quantia efetivamente entregue ao mutuário e a quantia por ele devida.

41 STEVENSON, cit., p. 10.

42 HUNGRIA, cit., p. 167, nota 1. Esse conceito, que Oscar Stevenson a um tempo endossa e questiona (op. cit., p. 11, nota 53) identifica comissões e juros, porque a distinção fica puramente nominal: os juros remunerariam o capital emprestado, enquanto as comissões remunerariam o serviço de emprestar o capital... Uma das múltiplas acepções da palavra comissão designa "a remuneração a que faz jus a comissão pelos trabalhos realizados" em favor do comitente (cf. MARTINS, Fran: Contratos e Obrigações Comerciais. ed. Forense, Rio, 1961, v. II. p. 322).

43 DE PLÁCIDO E SILVA: Vocabulário jurídico. ed. Forense Rio, 1962, v. II. p. 508. É esta acepção, própria do direito comercial, a única que se compatibiliza com a estrutura típica da usura pecuniária. Nesta acepção, para Maria Helena Diniz, desconto é o "abatimento feito no total de uma soma pecuniária ou no valor de uma obrigação" e também a "bonificação feita ao devedor pelo pagamento antecipado do débito" (DINIZ, Maria Helena: Dicionário Jurídico. ed. Saraiva, S. Paulo, 1998, v. 2. p. 88). Alguns autores se utilizam da acepção do direito cambiário ("prêmio ou juro devido pelo pagamento antecipado de um título de crédito ainda não vencido" - cf. DINIZ, cit.), o que tornaria obrigatória a formação de um título de crédito nesta submodalidade de usura pecuniária. 


\section{SOBRE USURA REAL.}

Transcrevamos o tipo legal da usura real (art. $4^{\circ}$, al. $b$ de lei 1521/51):

"obter ou estipular, em qualquer contrato, abusando da premente necessidade, inexperiência ou leviandade de outra parte, lucro patrimonial que exceda o quinto do valor corrente ou justo da prestação feita ou prometida."

Hungria observou, em seu momento, que a criminalização da usura real "veio ressuscitar em nosso direito, embora limitadamente, o instituto da lesão que o Código Civil banira" ${ }^{4}$. Não cabe aqui, agora que o novo código civil "ressuscitou" integralmente a lesão enorme (art. 157 CC), relembrar o debate acerca dos vínculos entre os dois institutos ${ }^{45}$, até porque o critério civilístico ("prestação manifestamente desproporcional") pouco pode auxiliar, por sua indeterminação, o critério típico de reconhecer o lucro excessivo a partir da superação de um quinto (20\%) do valor corrente ou justo da prestação.

Ao contrário da usura pecuniária, atrelada inexoravelmente a um contrato de mútuo (ostensivo ou simulado), a usura real pode ocorrer em "qualquer contrato", desde que comutativo, como o tipo legal esclarece ${ }^{46}$.

É indispensável que na contratação do lucro excessivo esteja o sujeito ativo "abusando da premente necessidade, inexperiência ou leviandade da outra parte". Este requisito da conduta deve ser considerado nos dois níveis do tipo complexo: no tipo objetivo, é indispensável a existência real de uma vítima hipossuficiente (pressionada pela necessidade, inexperiente ou leviana); no tipo subjetivo, é indispensável não só tenha o sujeito ativo conhecimento da hipossuficiência da vítima mas também tenha voluntariamente explorado tal hipossuficiência (dolo de aproveitamento).

"Premente necessidade" é a "opressiva e urgente precisão de meios para satisfazer inadiáveis obrigações" ${ }^{47}$. Inexperiência é a "falta de exato conhecimento dos negócios sobre que versar o contrato usurário",

44 Dos Crimes contra a Economia Popular, cit., p. 171.

45 Para uma notícia sobre o debate, para o qual contribuíram Orlando Gomes e Caio Mario da Silva Pereira, cf. BERNARDES BRAGA, Rodrigo: A Lei de Usura e os Excessos Praticados pelo Mercado Financeiro. ed. Palmar, Niterói, 1999. pp. 39 ss.

46 Repetem a expressão típica "qualquer contrato". DE OLIVEIRA, cit., p. 166 e SOUZA NETO. cit., p. 116; Oscar Stevenson menciona "contrato diverso" (do mútuo), pois estava diferenciando as duas modalidades de usura, cit., p. 9.

47 STEVENSON, cit., p. 16. Para Souza Neto, premente é "a necessidade incomum, quase sem saída, capaz de atormentar violentamente a consciência do necessitado", cit., p. 116. 
decorrente seja da rusticidade, seja da "falta de percepção adequada ou do entendimento relativo a coisas e fatos versados na convenção"48. "Leviandade" é "o descaso pelas consequências ulteriores dos próprios atos"49.

Pode-ao contrário da corrente histórica que concebia a usura estritamente como crime patrimonial ${ }^{50}$ - pode a necessidade ser extraeconômica ${ }^{51}$. No entanto, econômica ou não, deve a necessidade ser premente, atributo que por si só torna atípicas aquelas que poderíamos chamar de necessidades voluptuárias e de necessidades negociais, rotineiras ou especulativas. Só a necessidade premente, como assinalou Violante, "limita notavelmente, sem contudo excluí-la (senza escluderla) a vontade do sujeito, produzindo um verdadeiro e próprio vício" 52 . Foi "devido ao significado restritivo de premente" que Oscar Stevenson não reconheceu usura na hipótese de alguém que fosse explorado na venda de objetos para gastos que não representassem exigência indeclinável"53, tanto quanto Damianovich também não a reconhece quanto a alguém que tenha "o costume de passar férias em lugares de elevado custo e assim crie a 'necessidade' de procurar meios para pagá-los": esta não é uma "necessidade no sentido do tipo legal em análise" ${ }^{54}$.

Não só as necessidades voluptuárias da vítima tornam atípica a conduta do agente: também aquelas propriamente negociais, sejam elas rotineiras ou especulativas. Um comerciante em situação pré-falimentar pode estar em "premente necessidade"; outro que pretenda obter capital de giro para expansão de seu negócio não está. Já ensinava Hungria que "não se encontra em premente necessidade (...) uma pessoa que precise obter

48 DE OLIVEIRA, cit., p. 179.

49 Liszt-Schmidt, apud HUNGRIA, cit., p. 171.

50 "Apenas uma necessidade econômica (não por exemplo um perigo para a vida - nicht z. B. Lebensgefahr)" - proclamava VON LISZT, Lehrbuch, cit., p. 469; "uma outra necessidade não-econômica (por exemplo, sanitária) não basta (nicht genügt)" - repetia REINHARD, Frank: Das Strafgesetzbuch für das Deutsche Reich, ed. J.C.B.Mohr, Tubinga, 1931. p. 708.

51 "Não é preciso que a precisão (bisogno) tenha natureza expressamente econômica" (BONORA, Claudio: L'Usura. Cedam, Pádua, 2007. p. 17); “a situação de necessidade será quase sempre econômica, porém não é indispensável que tenha precisamente essa natureza" (MASNATTA, H. E BACIGALUPO, E.: Negocio Usurario, cit., p. 105).

52 VIOLANTE, Luciano: Il Delitto d'Usura. ed. Giuffrè, Milão, 1970. p. 51.

53 Aspectos do crime de usura, cit., p. 17.

54 Cf. El Delito de Usura, cit., p. 34. Acrescenta a A.: "o direito penal que justifica aquele que furta porque o faz para comer não há de reprimir a quem cobra elevado preço pelo dinheiro para pagar um luxo ou uma especulação daquele que pede" (p. 37). 
numerário para empregá-lo em algum negócio lucrativo", e em abono de seu entendimento invocava uma decisão do Supremo Tribunal alemão ${ }^{55}$. Endossou-lhe a lição Oscar Stevenson, negando haja premente necessidade em "quem deseje fundos para empreendimentos lucrativos" ${ }^{56}$. Trata-se de lição comum. Anotou Antolisei ser "bem natural (que) não se possa falar de estado de precisão (stato di bisogno) quando o dinheiro que se obtém é destinado a empregos produtivos" 57 . Pelo mesmo diapasão, considera Santoro inexistente o estado de precisão - o correspondente típico italiano de nossa premente necessidade - "no caso em que o contraente deseja efetuar uma especulação econômica, realizar um negócio lucrativo (un affare lucroso)" ${ }^{\prime 58}$.

Em suma, o tipo objetivo sistemático do delito de usura real requisita um sujeito passivo que esteja em premente necessidade; na falta dessa situação constrangedora (ausente perante necessidades voluptuárias ou negociais, rotineiras ou especulativas), o tipo requisita um sujeito passivo especialmente qualificado pela inexperiência (rústico ou desinformado sobre o contrato que está celebrando) ou pela leviandade (desatento às consequências dos próprios atos). Onde não existir premente necessidade da vítima, ou não for ela inexperiente ou leviana, também não existirá usura real.

O tipo subjetivo do delito de usura real requer o chamado "dolo de aproveitamento", constituído pela consciência da premente necessidade (ou da inexperiência ou ainda da leviandade) da vítima e pela vontade de explorá-las, de aproveitar-se delas para obter um ganho extraordinário. É indispensável "que o agente se tenha prevalecido da premente necessidade, inexperiência ou leviandade da outra parte para a obtenção ou estipulação do lucro exorbitante" observou Elias de Oliveira ${ }^{59}$. Também aqui estamos diante de lição comum. Segundo Logoz, "o autor deve não apenas ter tido consciência (avoir eu conscience) do estado de embaraço econômico (état de gêne)" da vítima (ou, no sentido do dolo eventual, ter contado seriamente com a existência daquele estado) mas também ter "consciente

55 Dos Crimes contra a Economia Popular, cit., pp. 169-170. O aresto alemão considerou que "não se encontra numa situação de necessidade (in einer Notlage) quem precisa fazer um sacrifício para auferir um lucro (um einen Gewinn zu realizieren)".

56 Aspectos do crime de usura, cit., p. 17.

57 ANTOLISEI, cit, p. 286.

58 SANTORO, Arturo: Manuale di Diritto Penale. ed. Utet, Turim, 1968, v. V. p. 421.

59 Crimes contra a Economia Popular, cit., p. 179. 
e voluntariamente explorado essa situação (exploité cette situation) ${ }^{" 60}$. Como, segundo Manzini, "o agente deve aproveitar (approfittare) do estado psicológico do sujeito passivo" (premido pela necessidade, ou confuso pela inexperiência, ou presa fácil pela leviandade), o dolo consiste na "consciência (consapevolezza) de aproveitar-se do estado de precisão de uma pessoa" ${ }^{\prime \prime}$. Trata-se de exigência presente em todos os crimes que envolvam dolo de aproveitamento. Por exemplo, no abuso de incapazes (art. $173 \mathrm{CP}$ ) - tal qual frisado por Magalhães Noronha - "é mister que o agente saiba que a vítima é um menor, um alienado ou um débil mental; é isso elemento integrante do dolo"62. A ignorância, por parte do sujeito ativo, da situação de premente necessidade em que se encontre a vítima ou de sua inexperiência ou leviandade constitui na usura real erro de tipo, que exclui o dolo (art. $20 \mathrm{CP}$ ).

Ao contrário de outros ordenamentos, que deixam em aberto o grau da exorbitância usurária, remetendo o juiz às práticas usuais ${ }^{63}$, o nosso - em harmonia com o regime de taxa máxima da usura pecuniária - o nosso estabelece um limite objetivo: será exorbitante apenas o lucro que ultrapasse o quinto (ou seja, 20\%) do valor corrente ou justo da prestação.

Valor corrente - critério que, quando possível acessá-lo, terá sempre preferência sobre o valor justo - é aquele valor de mercado, "o valor que assume um determinado bem ou serviço em dado momento e lugar, (...) é o valor usual, geral, comum" ${ }^{64}$. Tal valor é atribuído aos bens "por sua circulação frequente no mundo dos negócios"; é o valor "que eles comumente alcançam em dado lugar e determinado momento"65. Tratase aqui da communis aestimatio. Lapidarmente pronunciou-se Oscar Stevenson: "valor corrente é o preço que existe no mercado e no momento econômico para certos serviços e bens" ${ }^{\text {"6 }}$. $\mathrm{Na}$ unânime preocupação doutrinária de subordinar o "valor corrente" ao contexto temporal e local em que se celebrou o contrato ressoa algo da disciplina da lesão (cf. art.

60 LOGOZ, cit., p. 187.

61 MANZINI, Vincenzo: Trattato di Diritto Penale Italiano. ed. Utet, Turim, 1952, v. IX. pp. 758 e 777.

62 MAGAlHÃes NORONHA, Edgard: Crimes contra o Patrimônio. ed. Saraiva, S. Paulo, 1952, v. $2^{\circ}$. p. 300.

63 Como o alemão, cujo tipo legal (§ $291 S t G B)$ apenas requisita "manifesta desproporção com a prestação (auffälligen Missverhältnis zu der Leistung)".

64 HUNGRIA, cit., p. 173.

65 DE OLIVEIRA, cit., p. 180.

66 Aspectos do crime de usura, cit., p. 18. 
$\left.157, \S 1^{\circ} \mathrm{CC}\right)$. Em suma, só se recorrerá ao critério do "valor justo" quando impossível - por exemplo, tratando-se de res extra commercium - conhecer o valor corrente.

\section{BIBLIOGRAFIA.}

ANTOLISEI, Francesco: Manuale di Diritto Penale. Giuffrè, Milão, 1972, P.S., v. I.

ARISTÓTELES: A Política, 1258b). Cf. trad. de N.S.Chaves. Edipro, Bauru, 2009.

AZEVEDO, Noé: A repressão penal da usura em Estudos-homenagem a Nelson Hungria. Forense, Rio, 1962

BATISTA, Nilo: Matrizes Ibéricas do Sistema Penal Brasileiro. Revan, Rio, 2000

BERNARDES BRAGA, Rodrigo: A Lei de Usura e os Excessos Praticados pelo Mercado Financeiro. Palmar, Niterói, 1999

BONFANTE, Pietro: Instituciones de Derecho Romano, trad. L. Bacci e A. Larrosa. Reus, Madrid, 1965.

BONORA, Claudio: L'Usura. Cedam, Pádua, 2007

BOUZON, Emanuel (org.): As Leis de Eshunna. Vozes, Petrópolis, 1981.

Código de Hammurabi. Vozes, Petrópolis, 1976.

COING, Helmut: Derecho Privado Europeo, trad. A.P. Martín. Fund. Cult. Notariado, Madrid, 1996, v. I.

COSER, José Reinaldo: JUROS. LED, Leme, 2000.

DAMIANOVICH, Laura T.A.: El Delito de Usura. Ediar, B. Aires, 1971

DE BARROS MONTEIRO, Washington: Curso de Direito Civil. Saraiva, S. Paulo, 1962, v. $2^{\circ}$.

DE OLIVEIRA, Elias: Crimes contra a Economia Popular. F. Bastos, Rio, 1952

DE PLÁCIDO E SILVA: Vocabulário jurídico. Forense Rio, 1962 
DINIZ, Maria Helena: Dicionário Jurídico. Saraiva, S. Paulo, 1998

DUPONT-DELESTRAINT, Pierre: Droit Pénal des Affaires. Dalloz, Paris, 1974.

GONZAGA, Tomás A.: Carta sobre a Usura, em Obras Completas. INL, Rio, 1957, v. II

GOYET, F.: Droit Pénal Spécial, $8^{\mathrm{a}}$ ed. (rev. e at. por Rousselet, Patin e Arpaillange). Sirey, Paris, 1972

GRISPIGNI, Filippo: Diritto Penale Italiano. Giuffrè, Milão, 1950, v. II.

HUNGRIA, Nelson: Dos Crimes contra a Economia Popular. Jacintho, Rio, 1935

LANDROVE DIAZ, Gerardo: El Delito de Usura. Bosch, Barcelona, 1968

LA PORTA, Romualdo: Il Delitto di Usura. Ateneo, Roma, 1952

von LISZT, Franz: Lehrbuch des Deutschen Strafrechts. W. de Gruyter, Berlim, 1919

LOGOZ, Paul: Commentaire du Code Pénal Suisse. C. e Niestlé, Neuchâtel, 1955, P.S., v. I.

MAGALHÃES NORONHA, Edgard: Crimes contra o Patrimônio. Saraiva, S. Paulo, 1952, v. $2^{\circ}$.

MANTECCA, Paschoal: Crimes contra a Economia Popular e sua Repressão. Saraiva, S. Paulo, 1985

MANZINI, Vincenzo: Trattato di Diritto Penale Italiano. Utet, Turim, 1952 , v. IX.

MARTINS, Fran: Contratos e Obrigações Comerciais. Forense, Rio, 1961, V. II.

MASNATTA, Hector e BACIGALUPO, Enrique: Negocio Usurario. Astrea, B. Aires, 1972, ed. Astrea.

MOMMSEN, Theodor: Droit Pénal Romain. trad. J. Duquesne. A. Fontemoing, Paris, 1907 t. MOMMSEN, Theodor: Historia de Roma. trad. A. G. Moreno. Aguilar, Madri, 1957, v. I.

OLIVELLE, Patrick: Manu's Code of Law. Un. Oxford, N. Delhi, 2005. 
REINHARD, Frank: Das Strafgesetzbuch für das Deutsche Reich. J.C.B.Mohr, Tubinga, 1931

SANTARELLI, Umberto: La prohibición de la usura, de canon moral a regla jurídica. em Petit, Carlos (org.) .Del Ius Mercatorum al Derecho Mercantil. Marcial Pons, Madrid, 1997.

SANTORO, Arturo: Manuale di Diritto Penale. Utet, Turim, 1968, v. V

SILVAFRANCO, A. e StOCO, R.: Leis Penais Especiais e sua Interpretação Jurisprudencial. RT, S. Paulo, 2001

SOUZA NETO: Júri de Economia Popular. Forense, Rio, 1952

URE (h.), Ernesto: Usura en el Derecho Penal. Ab.-Perrot, B. Aires, 1967

VIOLANTE, Luciano: Il Delitto d'Usura. Giuffrè, Milão, 1970

WELZEL, Hans: Das Deutsche Strafrecht. W. de Gruyter, Berlim, 1969. 